\title{
220 半正定値計画法を用いた応力制約を有するトラスのロバスト性最大化
}

\author{
Robust Truss Optimization under Stress Constraints \\ by using Semidefinite Program
}

\author{
$\bigcirc$ 寒野 善博（京都大） 竹脇 出（京都大） \\ Yoshihiro KANNO and Izuru TAKEWAKI \\ Kyoto University, Sakyo, Kyoto 606-8501
}

\begin{abstract}
A robust truss optimization scheme, as well as an optimization algorithm, is presented based on the robustness function. Under the uncertainties of external forces modeled by using the info-gap decision theory, we formulate the maximization problem of the robustness function. A sequential semidefinite programming method is proposed which has the global convergent property. It is shown, in numerical examples, that optimum designs of various trusses can be found without any difficulty.
\end{abstract}

Key Words: Robust optimization, Info-gap model, Semidefinite program, Interior-point method, Successive linearization method

\section{1. 序}

近年，構造系が持つ種々のパラメータの不確定性に対 するロバスト性 (頑強性) を考慮した設計法が注目を集め ている. その多くは，不確定なパラメー夕の変動に対する 構造物の敏感性や信頼性を表す種々の指標を導入すること で，ロバストな設計を得ることを意図している [1-7].

構造系が持つパラメータの不確定性のモデルには，大 別して確率論的モデルと非確率論的モデルの 2 つがある. 確率論的不確定性モデルは, 例えば, 構造物の性能制約が 満たされない確率 (failure probability) を最小化する信 頼性設計に用いられる $[1,2]$. Doltsinis and Kang [3] は, 多目的最適化手法に基づき, 要求性能の期待値と標準 偏差の双方を最小化する問題を定式化した.

一方, 非確率論的な不確定性のモデルとしては, 凸モ デル (convex model) 解析 [8] がよく知られており，こ れに基づくトラスのロバスト最適化手法も提案されてい る [4]. また, Ben-Tal and Nemirovski.[9] は, 種々の 錐線形計画問題 [10] の倸数が不確定性を含む場合のロバ ス卜最適化の概念と手法を提案し, 不確定な外力を受ける トラスのコンプライアンス最小化問題を解いた [5]. Han and Kwak [6] は, 構造物の要求性能を定める関数の感度 係数の $l_{\infty}$ ノルムを最小化することで, 大きなロバスト性 を有する構造物を得る手法を提案した. 兽我部 [7] は多目 的最適化手法に基づき, 骨組の崩壊荷重の感度係数と構造 質量の双方を最小化する問題を定式化した.

Ben-Haim [11] はインフォ•ギャップ決定理論 (info-gap decision theory) に基づき，ロバスト性の指標としてロ バストネス関数 (robustness function) を提案した. ここ では，構造系のパラメータが非確率論的な不確定性を持つ ことを仮定し，その不確定性のレベルを 1 つのパラメータ $\alpha$ を用いて表す. ロバストネス関数 $\widehat{\alpha}$ は, 構造系が必ず性 能制約を满たすような $\alpha$ の最大值として定義される [12]. 確率論的な不確定性モデルに基づく信頼性理論では, 不 確定なパラメータの確率分布や変動の大きさを推定する必 要がある. 実際には, これらの統計量を正確に予測するこ とは極めて困難な場合が多い，これに対して，ロバストネ ス関数の利点は, 不確定なパラメータに関する統計量が一 切必要ないことである $[11,12]$. しかし， ロバストネス関 数を用いた構造物のロバスト最適設計法は, 著者らの知る 限り提案されていない.

本稿の目的は，不確定な外力を受けるトラスに対し，口 バストネス関数に基づく新しいロバスト設計法の枠組みと 解法を提案することにある.

ロバストネス関数は，無限個の制約条件を持つ数理計画 問題の最適値として定義される [11]. 従って，ロバストネ ス関数を求めること自体が，一般には極めて困難である. 本 稿ではまず, 応力制約を持つトラスに対し，そのロバストネ ス関数が半正定值計画問題 (semidefinite programming problem, SDP 問題) [10] を解くことで得られることを 示す. SDP は, 線形計画法や凸 2 次計画法などを含む凸 計画法であり, 主双対内点法と呼ばれる効率の良い解法が 知られている $[10]$. 次に, トラスのロバスト最適設計法 として，そのロバストネス関数を最大化する設計問題を定 式化する. さらに, SDP 問題を繰り返し解くことで, 最 適設計解を効率よく得る手法を提案する. 信頼領域法と類 似の考え方を用い，アルゴリズムが大域的収束性を持つこ とを示す.

\section{2. ロバストネス関数と半正定值計画法}

本稿では, ベクトル $\boldsymbol{p} \in \mathbf{R}^{n}$ の (Euclid) ノルムを 
$\|\boldsymbol{p}\|=\left(\boldsymbol{p}^{\top} \boldsymbol{p}\right)^{1 / 2}$ と書く. また, $n \times n$ 実対称行列全体の 集合を $\mathcal{S}^{n} \subset \mathbf{R}^{n \times n}$ で表す.

\section{1. 応力制約に関するロバストネス関数}

本節では，応力制約を持つトラスのロバストネス関数 が，無限個の制約条件を持つ数理計画問題の最適値として 得られることを示す.

3 次元空間内のトラスを考え, 微小変形および線形弾 性を仮定する．変位の自由度を $n^{\mathrm{d}}$ とおき， $\boldsymbol{u} \in \mathbf{R}^{n^{\mathrm{d}}}$ を 節点変位, $\boldsymbol{f} \in \mathbf{R}^{n^{\mathrm{d}}}$ を外力とする. トラスの剛性行列を $\boldsymbol{K} \in \mathcal{S}^{n^{\mathrm{d}}}$ とおくと, 釣合式は

$$
\boldsymbol{K} \boldsymbol{u}=\boldsymbol{f}
$$

で与えられる. 部材数を $n^{\mathrm{m}}$ とおき, 部材断面積から 構成されるべクトルを $\boldsymbol{a}=\left(a_{i}\right) \in \mathbf{R}^{n^{\mathrm{m}}}$ とする.こ こで, $\operatorname{rank}\left(\partial \boldsymbol{K} / \partial a_{i}\right)=1$ を用いると, 定べクトル $\boldsymbol{b}_{i}=\left(b_{i j}\right) \in \mathbf{R}^{n^{\mathrm{d}}}$ を用いて $\boldsymbol{K}$ は次式のように表すこ とができる.

$$
\boldsymbol{K}(\boldsymbol{a})=\sum_{i=1}^{n^{\mathrm{m}}} a_{i} \boldsymbol{b}_{i} \boldsymbol{b}_{i}^{\top} .
$$

ヤング係数を $E$, 第 $i$ 部材の許容応力を $\sigma_{i}^{\mathrm{c}}>0$ とおく と, (2)より, 応力制約は次式で与えられる.

$$
\left|\sqrt{E} \boldsymbol{b}_{i}^{\top} \boldsymbol{u}\right| \leq \sigma_{i}^{\mathrm{c}} \quad\left(i=1, \ldots, n^{\mathrm{m}}\right) .
$$

以下では，(3) を特別な場合として含む制約条件

$$
\begin{aligned}
\boldsymbol{u} \in \mathcal{F}:=\{ & \boldsymbol{u} \in \mathbf{R}^{n^{\mathrm{d}}} \mid \\
& \left.\left|\boldsymbol{d}_{l}^{\top} \boldsymbol{u}-v_{l}\right| \leq u_{l}^{\mathrm{c}}\left(l=1, \ldots, n^{\mathrm{c}}\right)\right\}
\end{aligned}
$$

を考える. ここで, $\mathbf{R}^{n^{\mathrm{c}}} \ni \boldsymbol{u}^{\mathrm{c}}=\left(u_{l}^{\mathrm{c}}\right) \geq \mathbf{0}, \boldsymbol{d}_{l} \in \mathbf{R}^{n^{\mathrm{d}}}$, $v_{l} \in \mathbf{R}\left(l=1, \ldots, n^{\mathrm{c}}\right)$ は定数である.

$\boldsymbol{f}$ の公称値を $\tilde{\boldsymbol{f}} \in \mathbf{R}^{n^{\mathrm{d}}}$ とおく. $\tilde{\boldsymbol{f}}, \alpha \geq 0$ に対し, $\boldsymbol{f}$ の不確定性集合 (uncertainty set) $\mathcal{T}(\alpha, \tilde{\boldsymbol{f}}) \subset \mathbf{R}^{n^{\mathrm{d}}}$ で表す. 本稿では, インフォ・ギャップモデル (info-gap model) [11] に基づき， $\mathcal{T}$ が不確定性を表すパラメータ $\boldsymbol{\zeta} \in \mathbf{R}^{n^{\mathrm{d}}}$ を用いて次のように表される場合を考える:

$$
\mathcal{T}(\alpha, \tilde{\boldsymbol{f}})=\{\widetilde{\boldsymbol{f}}+\boldsymbol{\zeta} \mid \alpha \geq\|\boldsymbol{\zeta}\|\} .
$$

不確定な外力 $\boldsymbol{f} \in \mathcal{T}(\alpha, \tilde{\boldsymbol{f}})$ に対する釣合式(1) の解 $\boldsymbol{u}$ 全 体の集合を $\mathcal{U}(\alpha, \boldsymbol{a}) \subseteq \mathbf{R}^{n^{\mathrm{d}}}$ とおく. 即ち，

$$
\begin{aligned}
\mathcal{U}(\alpha, \boldsymbol{a})=\left\{\boldsymbol{u} \in \mathbf{R}^{n^{\mathrm{d}}} \mid \boldsymbol{K}(\boldsymbol{a}) \boldsymbol{u}=\boldsymbol{f}\right. \\
\text { for some } \boldsymbol{f} \in \mathcal{T}(\alpha, \tilde{\boldsymbol{f}})\} .
\end{aligned}
$$

制約条件(4) に関するロバストネス関数 $\widehat{\alpha}: \mathbf{R}^{n^{\mathrm{m}}+n^{\mathrm{c}}} \mapsto$ $[0,+\infty]$ は, 次式で定義される (Ben-Haim [11, Ch. 3]).

$$
\begin{aligned}
& \alpha^{*}=\max \{\alpha: \boldsymbol{u} \in \mathcal{F} \quad \forall \boldsymbol{u} \in \mathcal{U}(\alpha, \boldsymbol{a})\}, \\
& \widehat{\alpha}\left(\boldsymbol{a}, \boldsymbol{u}^{\mathrm{c}}\right)= \begin{cases}\alpha^{*} & \text { (問題 (6) が実行可能), } \\
0 & \text { (問題 (6) が実行不能). }\end{cases}
\end{aligned}
$$

$\boldsymbol{a}^{1} \in \mathbf{R}^{n^{\mathrm{m}}}$ および $\boldsymbol{a}^{2} \in \mathbf{R}^{n^{\mathrm{m}}}$ が条件 $\widehat{\alpha}\left(\boldsymbol{a}^{1}, \boldsymbol{u}^{\mathrm{c}}\right)>$ $\widehat{\alpha}\left(a^{2}, u^{c}\right)$ を満たすとき, $a^{1}$ は $a^{2}$ よりもロバスト性が 大きいという. $\widehat{\alpha}\left(\boldsymbol{a}^{1}, \boldsymbol{u}^{\mathrm{c}}\right) \geq\left\|\boldsymbol{\zeta}^{1}\right\|$ を満たす $\boldsymbol{\zeta}^{1}$ に対して $\left|\boldsymbol{d}_{l}^{\top} \boldsymbol{u}-v_{l}\right|=u_{l}^{\mathrm{c}}$ が成立する $l \in\left\{1, \ldots, n^{\mathrm{c}}\right\}$ が存在する とき, $\zeta^{1}$ は最悪事例 (worst case) であるという.

このように，ロバストネス関数 $\widehat{\alpha}$ は問題 (6) の最適値 として得られる. しかし, 不確定パラメータ $\zeta$ は無限に 存在するため, 問題 $(6)$ は無限個の制約条件を含む. 従っ て，実際にその解を求めることは極めて困難である. そこ で，第 4 節では，問題 $(6)$ をSDP 問題に変換する.

\section{2. 半正定値計画問題}

半正定值対称行列全体の集合を $\mathcal{S}_{+}^{n} \subset \mathcal{S}^{n}$ で表す. 記号 $\boldsymbol{P} \succeq \boldsymbol{O}$ は $\boldsymbol{P} \in \mathcal{S}_{+}^{n}$ を, また $\boldsymbol{P} \succeq \boldsymbol{Q}$ は $\boldsymbol{P}-\boldsymbol{Q} \in \mathcal{S}_{+}^{n}$ を 意味する. 行列 $\boldsymbol{P}=\left(P_{i j}\right) \in \mathcal{S}^{n}$ と $\boldsymbol{Q}=\left(Q_{i j}\right) \in \mathcal{S}^{n}$ の 内積を $\boldsymbol{P} \bullet \boldsymbol{Q}=\sum_{i=1}^{n} \sum_{j=1}^{n} P_{i j} Q_{i j}$ で定義する.

$\boldsymbol{X} \in \mathcal{S}^{n}$ を変数とする次の数理計画問題を, 半正定値計 画問題 (semidefinite programming problem, SDP 問 題) の等式標準形の主問題と呼ぶ $[10]$.

$$
\left.\begin{array}{ll}
\min & \boldsymbol{C} \bullet \boldsymbol{X} \\
\text { s.t. } & \boldsymbol{A}_{i} \bullet \boldsymbol{X}=b_{i} \quad(i=1, \ldots, m), \\
& \mathcal{S}^{n} \ni \boldsymbol{X} \succeq \boldsymbol{O} .
\end{array}\right\}
$$

ここで, $\boldsymbol{A}_{i} \in \mathcal{S}^{n}(i=1, \ldots, m), \boldsymbol{b}=\left(b_{i}\right) \in \mathbf{R}^{m}$, $C \in \mathcal{S}^{n}$ は定行列および定べクトルである. 問題 (8) の双 対問題は, $\boldsymbol{y} \in \mathbf{R}^{m}$ を変数とする次の問題で与えられる.

$$
\left.\begin{array}{ll}
\max & \boldsymbol{b}^{\top} \boldsymbol{y} \\
\text { s.t. } & \boldsymbol{C}-\sum_{i=1}^{m} \boldsymbol{A}_{i} y_{i} \succeq \boldsymbol{O} .
\end{array}\right\}
$$

SDP 問題 (8) および $(9)$ の制約条件は, 線形行列不等式 (linear matrix inequality) と呼ばれ, 双方の問題の実行 可能領域は凸集合であることが知られている [10].

半正定値計画法は線形計画法や凸 2 次計画法などを含 んでおり, 従来よりも広い範囲の凸計画問題を扱うことが できる.さらに，主双対内点法と呼ばれる効率の良い解法 が提案され $[10]$, それに基づくソフトウェアもいくつか

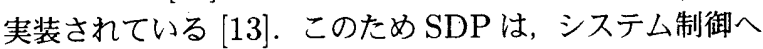
の応用, 組合せ最適化問題などの様々な分野で注目されて いる $[9,10]$. 著者らは, SDP を繰り返し用いることで, 線形座屈荷重係数の制約の下での構造物のトポロジー最適 化問題に対し，最適解で座屈荷重係数が多数重複する場合 にも効率よく解を得る手法を提案した [14].

\section{3. ロバストネス関数の例}

本節では，ロバストネス関数の概念を説明するために， Fig. 1 に示す 2 自由度トラスのロバストネス関数を解析 的に求める。節点 (a) はピン支持されており, 節点 (b) および (c) には，それぞれ，外力 $f_{1}$ および $f_{2}$ が作用す る. 節点 (b) および (c) の変位を $u_{1}$ および $u_{2}$ とおく. ま た, 部材 (1) と (2) の部材長は等しい. 部材断面積を $a_{i}$ $(i=1,2)$ とおくと, 部材応力 $\sigma_{i}$ は

$$
\sigma_{1}=\frac{f_{1}+f_{2}}{a_{1}}, \quad \sigma_{2}=\frac{f_{2}}{a_{2}}
$$


(a)

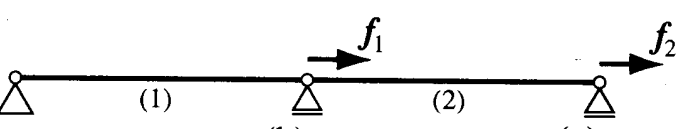

(b)

(c)

Fig. 1: Two-degrees-of-freedom truss.

で与えられる. 定数 $\sigma_{i}^{\mathrm{c}}>0$ を与え, 応力制約

$$
\left|\sigma_{i}\right| \leq \sigma_{i}^{\mathrm{c}} \quad(i=1,2)
$$

を考慮する.

$f_{1}$ および $f_{2}$ の公称值を $\tilde{f}>0$ とおく. インフォ・ギャッ プ不確定性モデル [11] に基づき， $\left(f_{1}, f_{2}\right)$ が不確定性パ ラメータらを用いて

$$
f_{1}=f_{2}=\tilde{f}+\zeta, \quad \alpha \geq|\zeta|, \quad \alpha \geq 0
$$

で表されることを仮定する. ただし，不確定集合の定義(12) は(4) とは異なる。 ロバストネス関数 $\widehat{\alpha}\left(\boldsymbol{a}, \boldsymbol{\sigma}^{\mathrm{c}}\right)$ の定義は, (12) を満たす任意の $\left(f_{1}, f_{2}\right)$ に対して条件 $(11)$ が満たさ れる $\alpha$ の最大值である. $\widetilde{f}>0$ より, 次式が得られる.

$$
\begin{aligned}
& \max _{\zeta \in \mathbf{R}}\left\{\left|\sigma_{1}\right|: \alpha \geq|\zeta|\right\}=\frac{2(\tilde{f}+\alpha)}{a_{1}}, \\
& \max _{\zeta \in \mathbf{R}}\left\{\left|\sigma_{2}\right|: \alpha \geq|\zeta|\right\}=\frac{\tilde{f}+\alpha}{a_{2}} .
\end{aligned}
$$

$\tilde{f}=9.8 \mathrm{~N}, \sigma_{i}^{\mathrm{c}}=1.96 \times 10^{4} \mathrm{~Pa}$ とおく. 以下の $2 \supset$ の部材断面積ベクトルを考える.

$$
\boldsymbol{a}^{1}=(15,15)^{\top} \mathrm{cm}^{2}, \quad \boldsymbol{a}^{2}=(20,10)^{\top} \mathrm{cm}^{2} .
$$

ただし， $a_{1}$ と $a_{2}$ の構造質量は等しい. 最初に $a=a_{1}$ と おく. (13)より, $\max \left\{\left|\sigma_{1}\right|: \alpha \geq|\zeta|\right\}$ は $\alpha=4.9 \mathrm{~N}$ にお いて $\sigma_{1}^{\mathrm{c}}$ に到達する. 一方, $\max \left\{\left|\sigma_{2}\right|: \alpha \geq|\zeta|\right\}$ は $\alpha=$ $19.6 \mathrm{~N}$ において $\sigma_{2}^{\mathrm{c}}$ に到達する. 以上より, $\widehat{\alpha}\left(\boldsymbol{a}^{1}, \boldsymbol{\sigma}^{\mathrm{c}}\right)=$ $4.9 \mathrm{~N}$ が得られる. 従って, 外力が $(12)$ および $\alpha \leq 4.9 \mathrm{~N}$ を満たすならば，制約条件(11) が必ず満たされる.また, 最悪事例 (worst case) は $f_{1}=f_{2}=14.7 \mathrm{~N}$ であり, こ のときに部材 (1)の応力制約がアクティヴになる. 同様に, $\boldsymbol{a}=\boldsymbol{a}^{2}$ に対して $\widehat{\alpha}\left(\boldsymbol{a}^{2}, \boldsymbol{\sigma}^{\mathrm{c}}\right)=9.8 \mathrm{~N}$ が得られる. 従つ $\tau, \widehat{\alpha}\left(\boldsymbol{a}^{1}, \boldsymbol{\sigma}^{\mathrm{c}}\right)<\widehat{\alpha}\left(\boldsymbol{a}^{2}, \boldsymbol{\sigma}^{\mathrm{c}}\right)$, 即ち, $\boldsymbol{a}^{2}$ は $\boldsymbol{a}^{1}$ よりもロバ スト性が大きいことが分かる.

一般のトラスに対しては，本節のようにロバストネス関 数を解析的に求めることは極めて困難である. 第 4 節で は， ロバストネス関数を効率よく求める手法を提案する.

\section{4. ロバストネス関数の SDP による定式化}

本節を通じて，問題 (6) が実行可能であることを仮定 する. 次の命題は, SDP を用いると問題 (6) の解が容易 に得られることを主張している.

命題 4.1. $t \in \mathbf{R}, \boldsymbol{\rho}=\left(\rho_{l}\right) \in \mathbf{R}^{n^{c}}, \boldsymbol{a} \in \mathbf{R}^{n^{\mathrm{m}}}$ に対し $\tau$, 行列 $\boldsymbol{G}_{l} \in \mathcal{S}^{n^{\mathrm{d}}+1}\left(l=1, \ldots, n^{\mathrm{c}}\right)$ を

$$
\begin{aligned}
& \boldsymbol{G}_{l}(t, \boldsymbol{\rho}, \boldsymbol{a})=\left(\begin{array}{ll}
\boldsymbol{G}_{l 11} & \boldsymbol{g}_{l 12} \\
\boldsymbol{g}_{l 12}^{\top} & g_{l 22}
\end{array}\right), \\
& \boldsymbol{G}_{l 11}=-\rho_{l} \boldsymbol{d}_{l} \boldsymbol{d}_{l}^{\top}+\boldsymbol{K}(\boldsymbol{a}) \boldsymbol{K}(\boldsymbol{a}), \\
& \boldsymbol{g}_{l 12}=\rho_{l} v_{l} \boldsymbol{f}_{l}-\boldsymbol{K}(\boldsymbol{a}) \tilde{\boldsymbol{f}}, \\
& g_{l 22}=-t+\tilde{\boldsymbol{f}}^{\top} \tilde{\boldsymbol{f}}
\end{aligned}
$$

で導入する. 与えられた $\left(\boldsymbol{a}, \boldsymbol{u}^{\mathrm{c}}\right) \in \mathbf{R}^{n^{\mathrm{m}}} \times \mathbf{R}^{n^{\mathrm{c}}}$ に対し， ロバストネス関数 $\widehat{\alpha}\left(\boldsymbol{a}, \boldsymbol{u}^{\mathrm{c}}\right)$ の 2 乗は $(t, \boldsymbol{\rho}) \in \mathbf{R} \times \mathbf{R}^{n^{\mathrm{c}}}$ を変数とする次の $\mathrm{SDP}$ 問題の最適值に一致する.

$$
\begin{aligned}
& \widehat{\alpha}\left(\boldsymbol{a}, \boldsymbol{u}^{\mathrm{c}}\right)^{2}=\max \left\{t: \boldsymbol{G}_{l}(t, \boldsymbol{\rho}, \boldsymbol{a})\right. \succeq \boldsymbol{O}, \\
&\left.\rho_{l} \geq 0 \quad\left(l=1, \ldots, n^{\mathrm{c}}\right)\right\} .
\end{aligned}
$$

証明. 行列 $\boldsymbol{Q}_{0 l}\left(i=1, \ldots, n^{\mathrm{c}}\right), \boldsymbol{Q}_{1}$ を

$$
\begin{aligned}
\boldsymbol{Q}_{0 l} & =\left(\begin{array}{cc}
-\boldsymbol{d}_{l} \boldsymbol{d}_{l}^{\top} & v_{l} \boldsymbol{d}_{l} \\
v_{l} \boldsymbol{d}_{l}^{\top} & \left(u_{l}^{\mathrm{c}}\right)^{2}-v_{l}^{2}
\end{array}\right), \\
\boldsymbol{Q}_{1} & =\left(\begin{array}{cc}
-\boldsymbol{K} \boldsymbol{K} & \boldsymbol{K} \tilde{\boldsymbol{f}} \\
\tilde{\boldsymbol{f}}^{\top} \boldsymbol{K} & \alpha^{2}-\tilde{\boldsymbol{f}}^{\top} \tilde{\boldsymbol{f}}
\end{array}\right)
\end{aligned}
$$

で定義する．このとき，条件 $u \in \mathcal{F}$ は

$$
\left(\boldsymbol{u}^{\top}, 1\right) \boldsymbol{Q}_{0 l}\left(\boldsymbol{u}^{\top}, 1\right)^{\top} \geq 0 \quad\left(l=1, \ldots, n^{\mathrm{c}}\right)
$$

に等価である. また，条件 $u \in \mathcal{U}$ は

$$
\left(\boldsymbol{u}^{\top}, 1\right) \boldsymbol{Q}_{1}\left(\boldsymbol{u}^{\top}, 1\right)^{\top} \geq 0
$$

に等価である，従って，問題 (6) の制約条件

$$
\boldsymbol{u} \in \mathcal{U} \quad \Longrightarrow \quad \boldsymbol{u} \in \mathcal{F}
$$

は, S-Lemma $[9, \S 4.10 .5]$ を用いると

$$
\exists \tau_{l} \geq 0, \quad \boldsymbol{Q}_{0 l}-\tau_{l} \boldsymbol{Q}_{1} \succeq \boldsymbol{O} \quad\left(l=1, \ldots, n^{\mathrm{c}}\right)
$$

に帰着できる. さらに, $\tau_{l}=0$ は $(16)$ を満たさないの で, (16) は

$$
\exists \rho_{l} \geq 0, \quad \rho_{l} \boldsymbol{Q}_{0 l}-\boldsymbol{Q}_{1} \succeq \boldsymbol{O} \quad\left(l=1, \ldots, n^{\mathrm{c}}\right)
$$

に等価である. 以上より，問題 (6) は

$$
\begin{gathered}
\widehat{\alpha}\left(\boldsymbol{a}, \boldsymbol{u}^{\mathrm{c}}\right)=\max \left\{\alpha: \boldsymbol{G}_{l}\left(\alpha^{2}, \boldsymbol{\rho}, \boldsymbol{a}\right) \succeq \boldsymbol{O},\right. \\
\left.\rho_{l} \geq 0 \quad\left(l=1, \ldots, n^{\mathrm{c}}\right)\right\}
\end{gathered}
$$

に帰着される. 問題 (17) において $\alpha$ を最大化するこ とは $\alpha^{2}$ を最大化することと等価であるので, 題意が 得られる.

元の問題 (6) が無限個の制約条件を持っているのに比 ベ, SDP 問題 (15)のサイズは $n^{\mathrm{d}}$ および $n^{\mathrm{c}}$ の多項式で 押さえられていることが重要である. さらに, 主双対内点 法 [10] を用いるとSDP 問題 (15) は容易に解くことがで 
きる. 従って, 命題 4.1 を用いると，ロバストネス関数を 効率よく求めることができる.

\section{5. ロバストネス関数最大化問題}

第 2.1 節で述べたように，ロバストネス関数が大きい ほど，トラスの持つロバスト性は大きいと考えられる．本 節の目的は，ロバストネス関数を最大化する部材断面積べ クトル $a$ を求めることである. 以降では，この構造最適 化問題をロバストネス関数最大化問題と呼ぶ.

$\boldsymbol{a}$ を変数とし, 部材の総体積に関する制約

$$
\sum_{i=1}^{n^{\mathrm{m}}} \ell_{i} a_{i} \leq \bar{V}
$$

を考慮する. ここで, $\ell_{i}$ は第 $i$ 部材の長さ, $\bar{V}>0$ は部 材の総体積の上限值である. $\boldsymbol{u}^{\mathrm{c}}$ および $\bar{V}$ をちると， 口 バストネス関数最大化問題注次式で定義される。

$$
\left.\begin{array}{ll}
\max _{\boldsymbol{a} \in \mathbf{R}^{n^{\mathrm{m}}}} & \widehat{\alpha}\left(\boldsymbol{a}, \boldsymbol{u}^{\mathrm{c}}\right) \\
\text { s.t. } & \boldsymbol{a} \geq \mathbf{0}, \quad \sum_{i=1}^{n^{\mathrm{m}}} \ell_{i} a_{i} \leq \bar{V} .
\end{array}\right\}
$$

ここで, 問題 (19) の目的関数を $\widehat{\alpha}\left(\boldsymbol{a}, \boldsymbol{u}^{\mathrm{c}}\right)^{2}$ に置き換えて も最適解が変わらないことに注意すると, 命題 4.1 より 問題 $(19)$ は $(t, \boldsymbol{\rho}, \boldsymbol{a}) \in \mathbf{R} \times \mathbf{R}^{n^{c}} \times \mathbf{R}^{n^{\mathrm{m}}}$ を変数とする 次の問題に帰着できる.

$$
\left.\begin{array}{ll}
\max & t \quad \\
\text { s.t. } & \boldsymbol{G}_{l}(t, \boldsymbol{\rho}, \boldsymbol{a}) \succeq \boldsymbol{O}, \quad \rho_{l} \geq 0 \\
& \left(l=1, \ldots, n^{\mathrm{c}}\right), \\
& \sum_{i=1}^{n^{\mathrm{m}}} \ell_{i} a_{i} \leq \bar{V}, \quad \boldsymbol{a} \geq \mathbf{0} .
\end{array}\right\}
$$

問題 $(20)$ は, $(t, \boldsymbol{\rho}, \boldsymbol{a})$ の非線形関数である行列 $\boldsymbol{G}_{l}$ が半 正定值である，という制約条件を含んでいる. そこで, 問 題 (20) を解くために, 逐次半正定値計画法を提案する.

以下では, 簡単のため $\boldsymbol{x}=(t, \rho, a)$ と書くことがあ る. (14) で定義される写像 $\boldsymbol{G}(\cdot)$ の $\boldsymbol{x}^{\prime}$ における微分を $D \boldsymbol{G}\left(\boldsymbol{x}^{\prime}\right)$ で表し，任意の $\boldsymbol{h}=\left(h_{i}\right) \in \mathbf{R}^{n^{\mathrm{c}}+n^{\mathrm{m}}+1}$ に対 して

$$
D \boldsymbol{G}\left(\boldsymbol{x}^{\prime}\right) \boldsymbol{h}=\left.\sum_{i=1}^{n^{\mathrm{c}}+n^{\mathrm{m}}+1} \frac{\partial \boldsymbol{G}_{l}(\boldsymbol{x})}{\partial x_{i}}\right|_{\boldsymbol{x}=\boldsymbol{x}^{\prime}} h_{i}
$$

を満たすように定義する. $(\Delta t, \Delta \rho, \Delta a) \in \mathbf{R} \times \mathbf{R}^{n^{c}} \times$ $\mathbf{R}^{n^{\mathrm{m}}}$ を変数とする次の SDP 問題を考える.

$$
\left.\begin{array}{ll}
\max & \Delta t-\frac{1}{2} c^{k}\|(\Delta t, \Delta \boldsymbol{\rho}, \Delta \boldsymbol{a})\|^{2} \\
\text { s.t. } & \Delta \boldsymbol{a}+\boldsymbol{a}^{k} \geq \mathbf{0}, \quad \Delta \boldsymbol{\rho}+\boldsymbol{\rho}^{k} \geq \mathbf{0} \\
& \sum_{i=1}^{n^{\mathrm{m}}} \ell_{i}\left(\Delta a_{i}+a_{i}^{k}\right) \leq \bar{V} \\
& D \boldsymbol{G}_{l}\left(t^{k}, \boldsymbol{\rho}^{k}, \boldsymbol{a}^{k}\right)(\Delta t, \Delta \boldsymbol{\rho}, \Delta \boldsymbol{a}) \\
& +\boldsymbol{G}_{l}\left(t^{k}, \boldsymbol{\rho}^{k}, \boldsymbol{a}^{k}\right) \succeq \boldsymbol{O} \\
& \left(l=1, \ldots, n^{\mathrm{c}}\right) .
\end{array}\right\}
$$

次のアルゴリズムは, 問題 $(20)$ の解を求める逐次 SDP 法である.

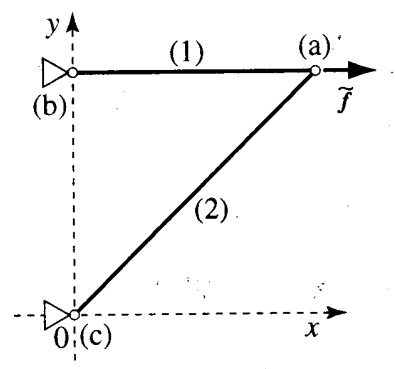

Fig. 2: 2-bar'truss.

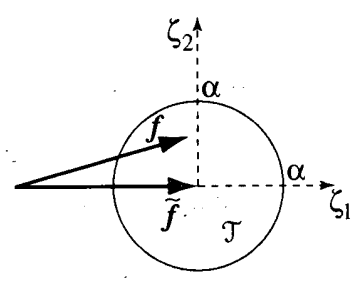

Fig. 3: Set $\mathcal{T}$ of uncertain external forces $\left(n^{\mathrm{d}}=2\right)$.
アルゴリズム 5.1 (問題(20) に対する逐次 SDP 法).

Step 0: (18) および $\widehat{\alpha}\left(a^{0}, u^{c}\right)>0$ を満たす $\boldsymbol{a}^{0} \geq$ 0 を選ぶ. また, $c^{0}>0, c_{\max } \geq c_{\min }>0, \epsilon>0$ を 選び, $k:=0$ とする.

Step 1: $\boldsymbol{a}=\boldsymbol{a}^{k}$ に対し, SDP 問題(15) の最適解 $\left(t^{k}, \rho^{k}\right)$ を求める.

Step 2: SDP 問題 (21) の最適解 $\left(\Delta t^{k}, \Delta \boldsymbol{\rho}^{k} ; \Delta \boldsymbol{a}^{k}\right)$ を求める. $\left\|\left(\Delta t^{k}, \Delta \boldsymbol{\rho}^{k}, \Delta \boldsymbol{a}^{k}\right)\right\| \leq \epsilon$ ならば, 反復終了.

Step 3: $\boldsymbol{a}^{k+1}:=\boldsymbol{a}^{k}+\Delta \boldsymbol{a}^{k}$, とおく.

Step 4: $c^{k+1} \in\left[c_{\min }, c_{\max }\right]$ を選び, $k \leftarrow k+1$ 亡 して Step 1 へ.

アルゴリズム 5.1 は，本質的に，信頼領域法を取り入 れた逐次 SDP 法 [15] に基づいている. 以下では, 適当 な仮定の下でアルゴリズム 5.1 の大域的収束性を示す. 以 下の 2 つの命題は, アルゴリズム 5.1 の Step 1 および Step 2 で解く SDP 問題が実行可能であることを保証し ている.

命題 5.2. $a \geq 0$ を満たす任意の $a \in \mathbf{R}^{n^{\mathrm{m}}}$ に対し, $(t, \rho)=\mathbf{0}$ は問題 $(15)$ の実行可能解である.

命題 5.3. $\boldsymbol{a}^{k} \geq \mathbf{0}$ および(18) を満たす $\boldsymbol{a}=\boldsymbol{a}^{k}$ に対 し, $\left(t^{k}, \rho^{k}\right)$ が問題 (15) の実行可能解であるならば, 問題 $(21)$ の最適解は一意に存在する.

また，アルゴリズム 5.1 の大域的収束性に関して，以 下の定理を導くことができる $[16]$.

定理 5.4. 問題 (21) の狭義実行可能性および $\tilde{\boldsymbol{f}} \neq 0$ を 仮定する. また, $\left\{\left(t^{k}, \boldsymbol{\rho}^{k}, \boldsymbol{a}^{k}\right)\right\}$ をアルゴリズム 5.1 で 生成される点列とする. このとき, 点列 $\left\{\left(t^{k}, \boldsymbol{\rho}^{k}, \boldsymbol{a}^{k}\right)\right\}$ のすべての集積点は問題 (20) の停留点である.

\section{6. 例題}

種々のトラスに対し，户ルゴリズム 5.1 を用いてロバ ストネス関数を最大化する設計解を求める.アルゴリズ ム 5.1 の Step 1 およびStep 2 では, 主双対内点法の実装 である SeDuMi Ver. 1.05 [13] を用いて SDP 問題を解 く. 不確定外力は (5) で定義されるため, 以下の例題では, トラスの全ての節点に任意の方向の外力が作用し得る.

\subsection{2 部材トラス}

Fig. 2 に示す 2 部材トラスを考える. 無応力状態におけ る部材 (1) および (2) の長さは, それぞれ $100 \mathrm{~cm}$ および 


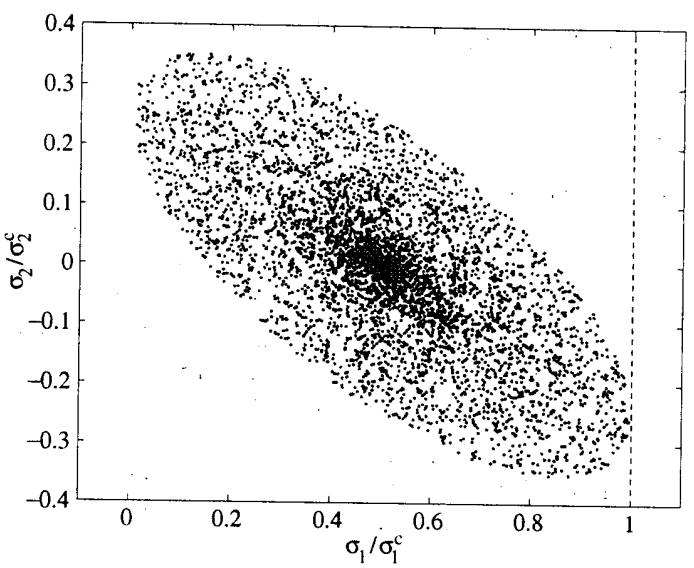

Fig. 4: Stress states of the 2-bar truss with the initial design $\boldsymbol{a}=\boldsymbol{a}^{0}$ for randomly generated $\boldsymbol{\zeta}$ satisfying (5) with $\alpha=\widehat{\alpha}\left(\boldsymbol{a}^{0}, \boldsymbol{\sigma}^{\mathrm{c}}\right)$.

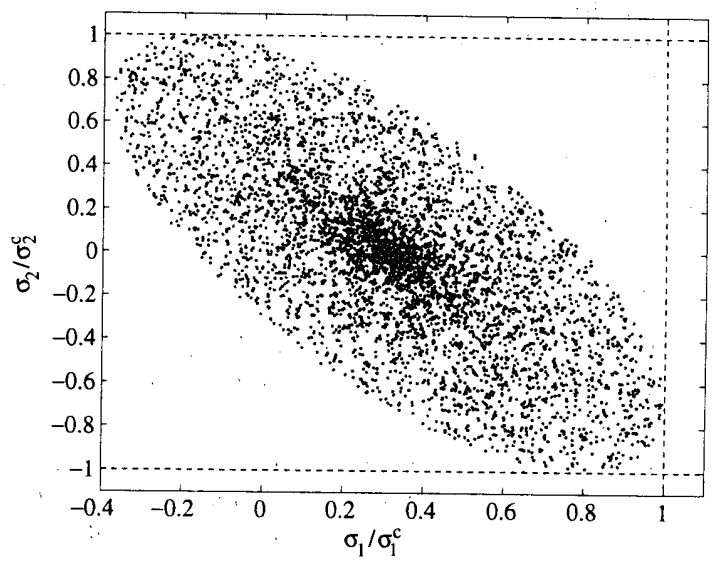

Fig. 5: Stress states of the 2-bar truss with the optimal design $\boldsymbol{a}=\boldsymbol{a}^{*}$ for randomly generated $\boldsymbol{\zeta}$ satisfying (5) with $\alpha=\widehat{\alpha}\left(\boldsymbol{a}^{*}, \boldsymbol{\sigma}^{\mathrm{c}}\right)$.

$100 \sqrt{2} \mathrm{~cm}$ である. 節点 (b), (c) はピン支持されており, $n^{\mathrm{d}}=2, n^{\mathrm{m}}=2$ である. 外力の公称值を $\widetilde{\boldsymbol{f}}=(98.0,0) \mathrm{N}$ で与える.このとき，(5) で定義される不確定外力 $f$ の集 合 $\mathcal{T}$ は, Fig. 3 に図示する円の境界および内部となる.さ らに $\sigma_{i}^{\mathrm{c}}=9.8 \times 10^{4} \mathrm{~Pa}$ とおいて, 各部材の応力制約 $(3)$ を考慮する.

アルゴリズム 5.1 の初期解を $\boldsymbol{a}^{0}=(20.0,40.0) \mathrm{cm}^{2}$ と選ぶ. このとき, 命題 4.1 に基づき, 主双対内点法を 用いて問題 $(15)$ を解くことで $\widehat{\alpha}\left(\boldsymbol{a}^{0}, \boldsymbol{\sigma}^{\mathrm{c}}\right)=69.297 \mathrm{~N}$ が 得られる. 次に, アルゴリズム 5.1 を用いてロバストネ ス関数最大化問題 $(20)$ を解く. アルゴリズム 5.1 におい $\tau, c^{k}=10^{-5}, \epsilon=0.05$. と選び, 部材の総体積の上限值 を $\bar{V}=76.5685 \mathrm{~cm}^{3}$ とおく, ただし， $\boldsymbol{a}=\boldsymbol{a}^{0}$ において 体積制約 $(18)$ がアクティヴである. 得られた最適設計解 は $\boldsymbol{a}^{*}=(32.1895,31.3807) \mathrm{cm}^{2}$ であり，このときにロ バストネス関数は $\widehat{\alpha}\left(\boldsymbol{a}^{*}, \boldsymbol{\sigma}^{\mathrm{c}}\right)=153.766 \mathrm{~N}$ である.

結果を検証するため, 条件を満たす $\zeta$ をランダムに生 成して対応する応力 $\sigma_{i}$ を求める. Fig. 4 は, 初期解 $\boldsymbol{a}^{0}$ に おいてランダムに作られた $\widehat{\alpha}\left(\boldsymbol{a}^{0}, \boldsymbol{\sigma}^{\mathrm{c}}\right) \geq\|\boldsymbol{\zeta}\|$ を満たす $\boldsymbol{\zeta}$ に対応する $\left(\sigma_{1} / \sigma_{1}^{\mathrm{c}}, \sigma_{2} / \sigma_{2}^{\mathrm{c}}\right)$ を示したものである. Fig. 4 に示される全ての場合において, 応力制約(3) が満たされ

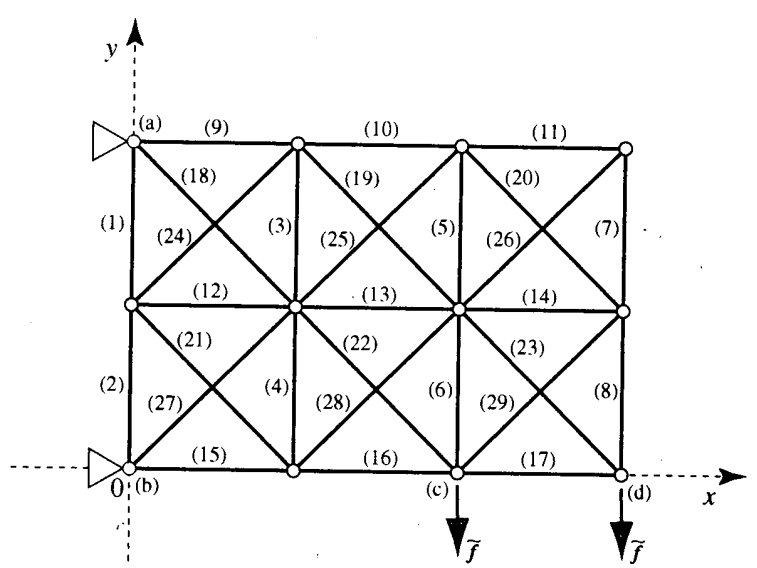

Fig. 6: 29-bar truss.

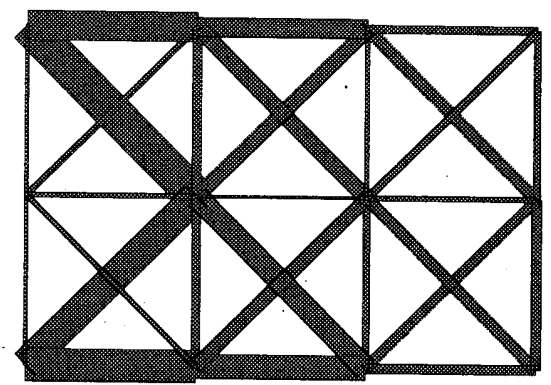

Fig. 7: Optimal design of the 29-bar truss.

ていることが分かる. また, 最悪事例は部材 (1) の制約条 件 $\sigma_{1} \leq \sigma_{1}^{\mathrm{c}}$ がアクティヴになる場合である. 一方, Fig. 5 は, 最適解 $\boldsymbol{a}^{*}$ において, $\widehat{\alpha}\left(\boldsymbol{a}^{*}, \boldsymbol{\sigma}^{\mathrm{c}}\right) \geq\|\boldsymbol{\zeta}\|$ を満たすよう にランダムに作られた $\boldsymbol{\zeta}$ に対応する $\left(\sigma_{1}, \sigma_{2}\right)$ を示してい る. Fig. 5 より, 応力制約 $(3)$ が常に満たされることが分 かる. また, 最悪事例では $\sigma_{1} \leq \sigma_{1}^{\mathrm{c}}, \sigma_{2} \leq \sigma_{2}^{\mathrm{c}}, \sigma_{2} \geq-\sigma_{2}^{\mathrm{c}}$ がアクティヴになり得る. 即ち, 最適化の結果, 部材 (1), (2) 双方の制約条件がアクティヴになり得る設計解が得ら れたことが分かる.

\subsection{9 部材トラス}

Fig. 6 に示す 29 部材トラスを考える. 節点 (a), (b) はピン支持されており, $n^{\mathrm{d}}=20, n^{\mathrm{m}}=29$ である. ま た， $x$ 軸お゙よび $y$ 軸方向の部材の自然長は $50.0 \mathrm{~cm}$ であ る. 外力の公称值 $\widetilde{\boldsymbol{f}}$ として, 節点 (c), (d) に $(0,-9.8) \mathrm{N}$ を作用させる. 外力の集合は(5) で定義されるため, 全て の節点に任意の方向の不確定外力が作用し得る.さらに $\sigma_{i}^{\mathrm{c}}=4.9 \times 10^{5} \mathrm{~Pa}$ とおき, すべての部材に対して応力 制約(3) を考慮する.

初期解を $a_{i}^{0}=20.0 \mathrm{~cm}^{2}\left(i=1, \ldots, n^{\mathrm{m}}\right)$ で与え, 命 題 4.1 を用いて $\widehat{\alpha}\left(\boldsymbol{a}^{0}, \boldsymbol{\sigma}^{\mathrm{c}}\right)=7.1161 \times 10^{-1} \mathrm{~N}$ を得る. また, $\bar{V}=3.3971 \times 10^{4}, \dot{\epsilon}=0.1, c^{k}=10^{-5}$ と選ぶ.

アルゴリズム 5.1 を用いて得られた最適解 $\boldsymbol{a}^{*}$ を Fig. 7 に示す.ここで, 各部材の幅は断面積に比例する.このと きのロバストネス関数は $\widehat{\alpha}\left(\boldsymbol{a}^{*}, \boldsymbol{\sigma}^{\mathrm{c}}\right)=10.8496 \mathrm{~N}$ である. 結果を検証するため, $a=a^{0}$ および $a=a^{*}$ において, それぞれ， $\widehat{\alpha}\left(\boldsymbol{a}^{0}, \boldsymbol{\sigma}^{\mathrm{c}}\right) \geq\|\boldsymbol{\zeta}\|$ および $\widehat{\alpha}\left(\boldsymbol{a}^{*}, \boldsymbol{\sigma}^{\mathrm{c}}\right) \geq\|\boldsymbol{\zeta}\|$ を 満たす $\zeta$ をランダムに生成し, 得られた $\sigma_{i} / \sigma_{i}^{\mathrm{c}}$ を Fig. 8 


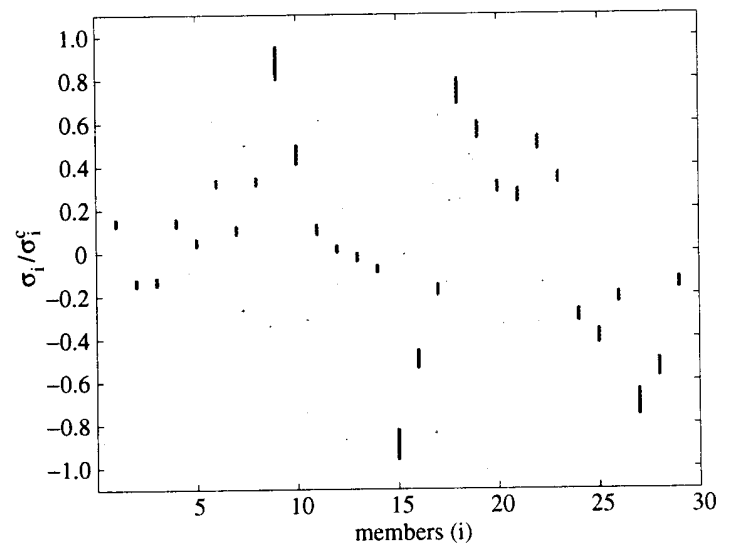

Fig. 8: Member stresses of the 29-bar truss with the initial design $\boldsymbol{a}=\boldsymbol{a}^{0}$ for randomly generated $\boldsymbol{\zeta}$ satisfying (5) with $\alpha=\widehat{\alpha}\left(\boldsymbol{a}^{0}, \boldsymbol{\sigma}^{\mathrm{c}}\right)$.

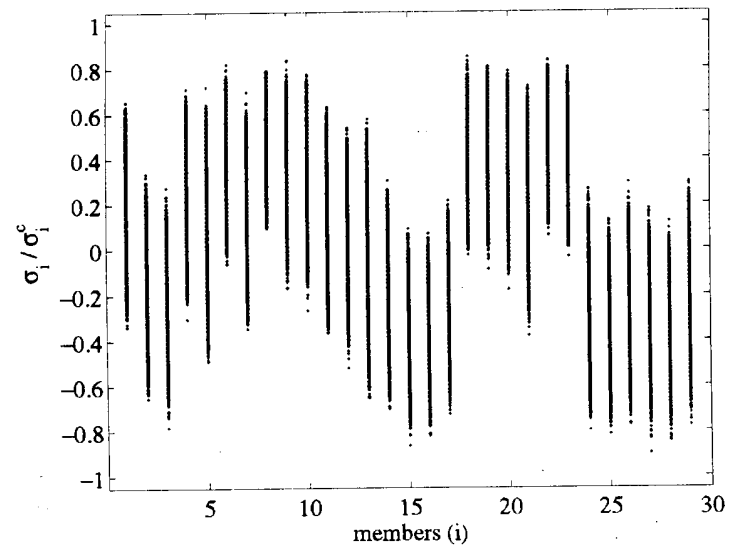

Fig. 9: Member stresses of the 29-bar truss with the optimal design $\boldsymbol{a}=\boldsymbol{a}^{*}$ for randomly generated $\boldsymbol{\zeta}$ satisfying (5) with $\alpha=\widehat{\alpha}\left(\boldsymbol{a}^{*}, \boldsymbol{\sigma}^{\mathrm{c}}\right)$.

および Fig. 9 に示す. Fig. 8 より, $a=a^{0}$ における最 悪事例は, 制約 $\sigma_{9} \leq \sigma_{9}^{\mathrm{c}}$ または $\sigma_{15} \geq-\sigma_{15}^{\mathrm{c}}$ がアクティ ヴになる場合であることが分かる. 一方，Fig. 9 に示すよ うに, $\boldsymbol{a}=\boldsymbol{a}^{*}$ ではほとんど全ての部材の応力制約がアク ティブになり得る.一般には，ランダムに生成した $\zeta$ が 正確な最悪事例に一致することはまれである．このため， Fig. 9 において，部材 (1), (2), (12), (13), (14) などの 断面積が比較的小さい部材に対する応力制約がアクティヴ となるらは得られていない。

\section{7. 結論}

本稿では，ロバストネス関数 [11] に基づくトラスのロ バスト最適設計法を定式化し，その最適解を効率良く得る 手法を提案した.

外力が不確定性を有する場合に，応力制約に関するト ラスのロバストネス関数を数理計画問題の最適値として定 式化した. また，この問題が半正定値計画問題に帰着でき ることを示した.

次に, トラスのロバスト最適設計問題として，体積制約 の下でロバストネス関数を最大化する問題を定式化した. 半正定值計画法を繰り返し解くことにより最適設計解を得 るアルゴリズムを提案し，その大域的収束性を示した。 ま
た, 種々の数值例題を通じ, 提案手法の有効性を例証した.

\section{参考文献}

[1] Kharmanda, G., Olhoff, N., Mohamed, A. and Lemaire, M., Reliability-based topology optimization, Struct. Multidisc. Optim., 26 (2004) 295-307.

[2] Choi, K.K., Tu, J. and Park, Y.H., Extensions of design potential concept for reliability-based design optimization to nonsmooth and extreme cases, Struct. Multidisc. Optim., 22 (2001) 335-350.

[3] Doltsinis, I. and Kang, Z., Robust design of structures using optimization methods, Comput. Meth. Appl. Mech. Engrg., 193 (2004) 2221-2237.

[4] Pantelides, C.P. and Ganzerli, S., Design of trusses under uncertain loads using convex models, $J$. Struct. Engrg. (ASCE), 124 (1998) 318-329.

[5] Ben-Tal, A. and Nemirovski, A., Robust truss topology optimization via semidefinite programming, SIAM J. Optim., 7 (1997) 991-1016.

[6] Han, J.S. and Kwak, B.M., Robust optimization using a gradient index: MEMS applications, Struct. Multidisc. Optim., 27 (2004) 469-478.

[7] 曽我部博之, 非線形感度によるロバス卜性を考虑し た平面骨組の最適塑性設計, 日本建築学会構造系論 文集, 556 (2002) 63-69.

[8] Ben-Haim, Y. and Elishakoff, I., Convex Models of Uncertainty in Applied Mechanics, Elsevier, New York, 1990.

[9] Ben-Tal, A. and Nemirovski, A., Lectures on Modern Convex Optimization: Analysis, Algorithms, and Engineering Applications, SIAM, Philadelphia, Pennsylvania, 2001.

[10] Wolkowicz, H., Saigal, R. and Vandenberghe, L. (eds.), Handbook of Semidefinite Programming Theory, Algorithms, and Applications, Kluwer Academic Publishers, Dordrecht, Netherlands, 2000.

[11] Ben-Haim, Y., Information-gap Decision Theory, Academic Press, London, UK, 2001.

[12] 竹脇出, 不確定性を有する構造物のロバスト性の非確 率的評価法, 日本建築学会構造系論文集, 581 (2004) $55-61$.

[13] Sturm, J.F., Using SeDuMi 1.02, a MATLAB toolbox for optimization over symmetric cones, Optim. Meth. Software, 11/12 (1999) 625-653.

[14] Kanno, Y., Ohsaki, M. and Katoh, N.; Sequential semidefinite programming for optimization of framed structures under multimodal buckling constraints, International Journal of Structural Stability and Dynamics, 1 (2001) 585-602.

[15] Kanzow, C., Nagel, C. and Fukushima; M., Successive linearization methods for nonlinear semidefinite programs, Technical Report 2003-011, Department of Applied Mathematics and Physics, Kyoto University, August 2003.

[16] Kanno, Y. and Takewaki, I., Sequential semidefinite program for robust truss optimization based on robustness functions associated with stress constraints, BGE Research Report 04-05, Building Geoenvironment Engineering Laboratory, Kyoto University, Japan, July 2004. 